\title{
Avanços Metodológicos no Estudo das Falsas Memórias: Construção e Normatização do Procedimento de Palavras Associadas
}

\author{
Methodological Advances in False Memory Research: \\ Development and Norming of DRM Procedure
}

\author{
Lilian Milnitsky Stein ", Leandro da Fonte Feix \& Gustavo Rohenkohl \\ Pontificia Universidade Católica do Rio Grande do Sul, Porto Alegre, Brasil
}

\begin{abstract}
Resumo
O procedimento de Roediger e McDermott (1995), que utiliza listas de palavras associadas, vem sendo utilizado no mundo inteiro pela sua comprovada eficácia no estudo experimental das falsas memórias. Foram realizados dois estudos com o propósito de construir e normatizar listas de palavras semanticamente associadas, adaptadas para a realidade brasileira. O Estudo I $(\mathrm{n}=426)$ descreve o processo de construção de 44 listas de palavras associadas, incluindo oito listas de palavras com conteúdo emocional. O Estudo II (n=471) apresenta os primeiros dados normativos sobre a produção de falsas memórias em adultos, a partir das listas geradas no primeiro estudo. As normas para as listas de palavras associadas foram elaboradas e testadas para duas condições de testagem da memória: recordação livre e reconhecimento. Os resultados retratam o poder do procedimento de palavras associadas para a investigação experimental das falsas memórias

Palavras-chave: Memória; falsas memórias; palavras associadas; recordação; reconhecimento.
\end{abstract}

\begin{abstract}
The Roediger e McDermott, (1995) Word List Paradigm has been widely used as a powerful experimental technique to investigate false memories. Two studies were designed with the purpose of developing and creating norms for lists of semantically related words for Brazilian Portuguese. Study $1(\mathrm{n}=426)$ describes the process of generating 44 word lists, including eight emotional lists. Study II $(n=471)$ provides the first normative data on false memories production using the lists developed in the first study. Normative data includes two memory-testing conditions: free recall and recognition. Results indicate the effectiveness of the word lists paradigm for studying false memories.

Keywords: Memory; false memory; DRM; recall; recognition.
\end{abstract}

O fenômeno da distorção e falsificação da memória vem interessando pesquisadores desde os primórdios do século XX. Os primeiros experimentos específicos sobre as distorções na memória estavam relacionados à sugestionabilidade em crianças, e foram realizados por Binet, em 1900, na França e, posteriormente, por Stern em 1910, na Alemanha (citado por Ceci, \& Bruck, 1993). Outro precursor dos estudos sobre as falsas memórias, porém em adultos, foi Bartlett (1932). Em 1932, ele realizou seu conhecido experimento valendo-se de um mito indígena. Para Bartlett, as distorções na memória ocorreriam devido ao fato de que o recordar seria um processo re-construtivo, baseado em esquemas gerados a partir do meio cultural e conhecimentos prévios da pessoa.

No final da década de 50, Deese (1959) publicou um artigo sobre a criação de listas de palavras, baseadas nas normas de associação semântica de Kent-Rosanoff (Russell \& Jenkins, 1954). O objetivo de Deese era verificar como

\footnotetext{
* Endereço para correspondência: Pós-Graduação em Psicologia, PUCRS, Av. Ipiranga, 6681, prédio 11, sala 933, Porto Alegre, RS, 90619-900. Fone: (51) 3320 3500, R: 7741; Fax: (51)33203633. E-mail: lilian@pucrs.br Apoio CNPq.
}

fatores associativos semânticos afetariam a recordação de palavras, além de medir os índices de intrusões que cada lista produzia.

Mais de três décadas depois, Roediger e McDermott (1995) retomaram o procedimento originalmente proposto por Deese (1959), adaptando vinte e quatro listas de 15 palavras semanticamente associadas, tendo por base o dicionário de Russell e Jenkins (1954), mesma fonte utilizada no artigo original de Deese. Nesse estudo, Roediger e McDermott mostraram a robustez deste procedimento para estudar as ilusões mnemônicas, ou seja, as falsas memórias: lembranças de eventos que, na realidade, nunca ocorreram (Stein \& Neufeld, 2001).

No procedimento com palavras associadas, listas de palavras são apresentadas para serem memorizadas. As palavras de cada lista giram em torno de um mesmo tema (e.g., som, dança, disco, ritmo, melodia, cantor, letra, rádio, violão, instrumentos, notas, harmonia, ouvir, voz, guitarra, versam sobre o tema música). A palavra crítica - música - que traduz a essência temática da lista e que está semanticamente associada a todas as palavras da mesma lista, não é apresentada na etapa de memorização. O efeito consistente que se observa é que, quando testada a memória para a 
lista original, a palavra música é recordada ou reconhecida muitas vezes na mesma proporção que palavras da lista estudada. Como repercussão da publicação do artigo de 1995 ocorreu uma proliferação de trabalhos valendo-se do procedimento experimental com listas de palavras associadas, que também ficou conhecido como paradigma de Deese-Roediger-McDermott (DRM).

Para se ter uma idéia da reviravolta ocorrida no meio científico com a publicação do artigo de Roediger e McDermott, pode-se observar os seguintes dados: em 36 anos, desde 1959, ano de publicação do artigo de Deese, até 1995, ano de publicação do ar tigo de Roediger e McDermott, havia apenas 42 citações do artigo de original de Deese. Em dez anos, desde a publicação do trabalho de Roediger e McDermott (1995) até 2005, o mesmo artigo de 1959 teve 325 citações e, além disso, o ar tigo de Roediger e McDermott obteve 527 citações (Social Sciences Citation Index, 2005).

Numa revisão histórica, Bruce e Winograd (1998) ilustraram a influência do zeitgeist na ciência, traçando uma comparação entre os artigos de Deese (1959) e de Roediger e McDermott (1995). Os autores buscaram apontar qual o motivo de dois artigos publicados em diferentes épocas, mas que utilizaram o mesmo procedimento experimental, causarem impactos tão distintos no meio científico. Segundo Bruce e Winograd, no início da década de 90 observou-se um crescente interesse no estudo da validade de memórias recuperadas por adultos acerca de episódios de abuso sexual na infância. Isto fez com que os pesquisadores dessa área se tornassem especialmente interessados na questão da inacurácia da memória, levando a um aumento significativo no número de publicações sobre as distorções mnemônicas. Roediger (1996) corrobora essa hipótese afirmando que esse fenômeno se explicaria pelo crescimento do interesse em estudos sobre a gênese destas distorções, ocorrido na década de 90, uma vez que, em 1959, os erros de memória não eram foco das investigações experimentais em Psicologia.

Quatro anos após o estudo de Roediger e McDermott (1995), Stadler, Roediger e McDermott (1999) incluíram mais 12 listas ao procedimento DRM, e criaram normas norte-americanas para a produção de falsas memórias. Estas normas foram criadas através da testagem das 36 listas, com 205 universitários americanos, para duas condições de teste de memória: recordação livre e reconhecimento.

Desde então, inúmeros estudos (Anastasi, Rhodes \& Burns, 2000; Balota et al., 1999; Dodson \& Schacter, 2002; Gallo \& Roediger, 2002; Neuschatz, Benoit \& Payne, 2003; Watson, Balota \& Roediger, 2003; Watson, McDermott \& Balota, 2004) vêm utilizando esse procedimento de diversas maneiras, como um bom modelo experimental que produz efeitos robustos na investigação das falsas memórias.

O primeiro estudo brasileiro a utilizar o procedimento DRM foi realizado por Stein e Pergher (2001). Foram traduzidas e adaptadas para o português 10 das 36 listas de Stadler et al. (1999) e, posteriormente, aplicadas em 60 universitários brasileiros. A memória foi verificada através de testes de reconhecimento. Nesse estudo de Stein e Pergher, foi investigado o efeito do momento da testagem nas memórias verdadeiras e falsas, e a persistência dessas memórias por um período de uma semana. Verificou-se, também, o efeito de um teste de memória anterior sobre um teste posterior. Os resultados desse estudo demonstraram a eficácia do procedimento para o estudo das falsas memórias para a população adulta brasileira. Além disso, foi observado que um simples teste de memória imediato aumentava os níveis de memória verdadeira e falsa no teste posterior e que, com a passagem do tempo, os índices de falsas memórias superavam àqueles das memórias verdadeiras.

Todavia, as limitações inerentes à mera tradução e adaptação das listas de palavras, em que a questão da adequação cultural do material ficou muito prejudicada, motivou-nos a, no presente trabalho, construir e normatizar novas listas de palavras semanticamente associadas para o Português Brasileiro. Além das 36 listas, abrangendo campos semânticos semelhantes aqueles de Stadler et al. (1999), foram incluídas oito novas listas de palavras com conteúdo emocional. A inclusão da variável "Emoção" no material brasileiro foi uma inovação que buscou fornecer subsídios para futuras pesquisas no âmbito da relação entre emoção e memória. Para atingir os objetivos pretendidos foram conduzidos dois estudos. No primeiro estudo foi desenvolvido o processo para a construção das listas de palavras associadas brasileiras. Já o segundo estudo buscou produzir os primeiros dados normativos para a produção de falsas memórias em adultos, valendo-se das listas geradas no primeiro estudo. A versão brasileira do DRM foi por nós denominada de Procedimento de Palavras Associadas.

\section{Estudo I}

Neste primeiro estudo, buscamos construir 44 listas, contendo 15 palavras por lista, para adaptação e normatização do Procedimento de Palavras Associadas para a realidade brasileira. O estudo foi aprovado pelo Comitê de Ética em Pesquisa da PUCRS (490/O1-CEP, 18/12/2001).

\section{Método}

O método utilizado para construção das listas baseou-se naqueles empregados por Janczura (1996), bem como, por Russell e Jenkins (1954). Este último também utilizado por Deese (1959) para criação do procedimento original.

\section{Participantes}

A amostra foi composta por 426 estudantes universitários, escolhidos por conveniência, 283 do sexo feminino e 143 do masculino, de cinco universidades públicas e particulares dos estados do Rio Grande do Sul, São Paulo e Paraná. A idade média dos participantes era de 23,27 anos $(d p=6,64)$, sendo sua participação voluntária e anônima.

\section{Instrumentos}

Inicialmente, foram traduzidas por quatro juízes com proficiência em Língua Inglesa as 36 palavras críticas 
(p.ex., música) das listas de Stadler et al. (1999), aqui designadas como palavras geradoras originais. Destas 36 listas havia apenas uma com evidente conteúdo emocional, cuja palavra crítica era raiva. Agregaram-se a estas, oito novas palavras geradoras emocionais representando distintas emoções básicas: quatro palavras para emoções positivas (alegria, alívio, paixão, satisfação) e quatro negativas (culpa, dor, mágoa, medo). Tais palavras emocionais foram selecionadas por três psicólogos clínicos (com, no mínimo, dez anos de experiência), baseados em critérios de categorização das emoções propostos por Ekman (1999).

Com o objetivo de definir o melhor formato de apresentação do material para a coleta das palavras a serem geradas pelos participantes, foi conduzido um estudo piloto com estudantes universitários $(\mathrm{N}=96)$. Com base na testagem piloto, definiu-se por dividir as 44 palavras geradoras em dois conjuntos de 22 palavras (conjunto A e conjunto B). Em cada conjunto, as 22 palavras geradoras foram dispostas em pequenos blocos, contendo uma palavra impressa no topo de cada folha, com três linhas abaixo de cada uma delas.

\section{Procedimentos}

A coleta definitiva deu-se em cinco universidades públicas e particulares nos estados do Rio Grande do Sul, Paraná e São Paulo. Os dados foram coletados em apenas uma sessão, na sala de aula dos próprios alunos, e os participantes que aceitavam fazer parte do estudo assinavam um termo de consentimento livre e esclarecido, elaborado consoante as diretrizes éticas que regulamentam a pesquisa com seres humanos. Em seguida eram explicados os objetivos da pesquisa e iniciada a coleta propriamente dita. Os participantes foram distribuídos aleatoriamente a cada um dos dois conjuntos de palavras, de tal modo que praticamente à metade da amostra foi apresentado o conjunto $\mathrm{A}$ e à outra metade, o conjunto $\mathrm{B}$.

Os participantes eram então solicitados a escrever, nas três linhas em branco de cada folha, as palavras que julgassem mais associadas semanticamente à palavra impressa no topo da mesma. Nas instruções era dado um exemplo, em que biblioteca era a palavra geradora, impressa na folha, e livro a primeira palavra gerada, seguida por silêncio e catálogo. Salientava-se que as três palavras tinham um significado associado à idéia de biblioteca, porém as palavras não possuíam uma relação direta de sentido entre si. Esse procedimento buscou minimizar os possíveis efeitos de geração de palavras associadas à palavra produzida anteriormente, e não à palavra impressa no topo da folha.

\section{Tratamento dos Dados e Resultados}

Com todas as palavras geradas para cada uma das 44 palavras geradoras pelos participantes foi criado um banco de dados com um total de aproximadamente 7.200 palavras geradas. Cada uma das 44 listas continha, em média, 160 palavras diferentes associadas semanticamente à palavra geradora em questão. $\mathrm{O}$ desafio do tratamento desses dados era que esse grande número de palavras fosse reduzido para apenas 15 palavras por lista.
O primeiro passo foi excluir do cômputo de cada lista aqueles participantes que não respondessem às três palavras solicitadas no protocolo. Foi então realizada uma avaliação do grau de associação semântica de cada palavra gerada com aquela geradora correspondente. $\mathrm{O}$ cálculo da força associativa $(F A)$ era constituído pelo produto da freqüência das palavras $(f)$ e a média do valor da posição (Mpos) de cada palavra escrita $(F A=f \times$ M Mos). A Mpos foi calculada considerando a posição em que cada palavra era escrita no bloco, assim, para a primeir a palavra escrita era atribuído o peso três, para a segunda, peso dois e para a terceira palavra peso um. Por fim, foram excluídos todos nomes próprios das listas.

Depois de calculada a $F A$ das palavras geradas, deu-se início às primeiras análises para construção das 44 listas de palavras associadas. Estas análises foram denominadas de intra-listas, pois foram realizadas análises independentes somente dentro de cada uma das 44 listas. Em consulta a um lingüista, especialista em semântica, ficou estabelecido que todos os vocábulos com a mesma raiz morfológica fossem agrupados em uma só palavra que possuía a maior FA dentre elas. Para a identificação da raiz morfológica das palavras, foi utilizado o Dicionário Morfológico da Língua Portuguesa (Heckler, 1984). A seguir, foram excluídas quaisquer palavras que possuíssem a mesma raiz que a palavra geradora. Por fim, foi feita uma conferência das palavras resultantes quanto a sua existência na língua portuguesa (Ferreira, 1999).

Ao término das análises intra-listas, havia-se chegado em listas ainda com um número muito grande de palavras (acima de 15). Dessa forma, deu-se início à análise entrelistas, que, ao contrário da análise anterior, tratou todas as 44 listas como se fossem uma única, a fim de excluírem-se palavras que se encontravam repetidas em mais de uma das listas.

Primeiramente foram selecionadas as 25 palavras de maior FA de cada uma das 44 listas. Em seguida, com auxílio de ferramentas de gramática e ortografia do programa Word 2000 para Windows 2000, eliminaram-se as palavras idênticas repetidas ou de mesmo radical, variantes de prefixação ou sufixação, optando-se por manter aquela palavra que apresentasse a maior FA. Em caso de palavras com força associativa equivalente, foi realizada uma avaliação conjunta por três juízes para eleição de qual das palavras com mesma FA comporia a lista final. Esta avaliação foi feita levando-se em conta a contribuição da palavra na coerência semântica da lista a qual pertencia. Ao cabo do processo das análises intra e entre-listas, obteve-se 44 listas contendo as 15 palavras com maior associação semântica as suas respectivas palavras geradoras (Anexo).

\section{Estudo II}

O presente estudo teve por objetivo principal gerar indicadores relativos a memórias verdadeiras e falsas a partir da utilização das listas produzidas no Estudo I. 
Stein, L.M.; Feix, L.F., \& Rohenkohl, G. (2006). Avanços Metodológicos no Estudo das Falsas Memórias: Construção e Normatização do Procedimento de Palavras Associadas.

\section{Método}

O método empregado baseou-se em Stadler et al. (1999), com duas inovações: a inclusão de listas emocionais, e a dissociação entre os testes de memória. Assim, as 44 listas de palavras associadas desenvolvidas no Estudo I, sendo nove delas com conteúdo emocional (cinco com valência emocional negativa e quatro com positiva), foram avaliadas para duas condições independentes de testagem da memória: recordação livre e reconhecimento.

\section{Participantes}

Participaram desse estudo 471 estudantes de distintos cursos de graduação, de universidades públicas e particulares do Rio Grande do Sul e do Paraná, com idade média de 22,08 anos $(d p=5,72)$, de ambos os sexos $(41,3 \%$ masculino e $58,7 \%$ feminino). A amostra foi escolhida por conveniência, sendo a participação voluntária e anônima.

\section{Instrumentos}

As 44 listas (ver Anexo) foram divididas em três blocos para compor o material original, de modo que cada bloco contivesse 15 listas, cada uma delas com 15 palavras. Para homogeneizar o tamanho dos blocos, foi necessário repetir uma das listas. Em virtude disso, por escolha aleatória, a lista homem foi incorporada nos blocos 1 e 3, totalizando 225 palavras por bloco. Ainda quanto a constituição dos blocos, também se observou o critério de distribuição eqüitativa das listas no que tange sua força associativa e emocionalidade, de tal forma que, cada bloco foi constituído por: 12 listas de palavras com valência neutra e 3 com valência emocional (positiva ou negativa), ordenadas aleatoriamente. O material original foi áudio gravado digitalmente por uma locutora profissional, que apresentava um intervalo de dois segundos entre cada palavra.

O teste de recordação livre era constituído por 15 folhas de papel numeradas, correspondendo a cada uma das listas apresentadas no material original. Já o teste de reconhecimento foi construído para cada um dos blocos de listas de palavras apresentadas no material original. Seguindo este critério, foram selecionadas as palavras que ocupavam a posição um, oito e dez, de cada uma das 15 listas originais do bloco a que pertenciam. Estas 45 palavras constituíram os itens alvo do teste de reconhecimento (ou seja, palavras que foram apresentadas no material original). Além desses itens alvo, o teste também incluía 15 distratores críticos (as palavras críticas que resumiam a essência semântica da lista e que não haviam sido incluídas no material original, por exemplo, música) e 30 distratores não relacionados (palavras que não possuíam associação semântica com nenhum dos itens do material original). Assim, foram confeccionados três testes de reconhecimento, correspondentes a cada um dos três blocos de palavras do material original. Cada teste de reconhecimento continha 90 palavras, aleatoriamente ordenadas, em três colunas numa folha de papel A4.

\section{Procedimentos}

As turmas de alunos, às quais os participantes pertenciam, foram distribuídas aleatoriamente em dois grandes grupos, quais sejam: o grupo que realizou o teste de recordação livre (Grupo de Recordação, $n=190$ ) e o grupo que realizou somente o teste de reconhecimento (Grupo de Reconhecimento, $n=281$ ). Foi designado aleatoriamente, a cada uma das turmas de alunos, um dos três blocos do material original.

Os procedimentos relativos à ética na pesquisa foram tomados em conformidade com a legislação nacional, tendo sido aprovados pelo Comitê de Ética em Pesquisa da PUCRS (490/O1-CEP). Sendo assim, somente os universitários que assinaram o termo de consentimento livre e esclarecido é que participaram da pesquisa. Eles foram testados em grupo na própria sala da turma, em uma única sessão, em períodos de aula cedidos pelo docente responsável pela disciplina. Os participantes foram instruídos a ouvirem com atenção o material original, pois a memória deles para aquelas palavras iria ser testada posteriormente. Os procedimentos foram diferentes para cada grupo, em virtude disso, serão apresentados separadamente.

No Grupo de Recordação, a coleta de dados foi composta por duas etapas: (a) apresentação das listas; e (b) teste de recordação livre. Cada lista de 15 palavras do material original era apresentada em áudio utilizando-se um aparelho de som portátil. Para o teste de recordação livre, após a apresentação de cada lista, fazia-se uma pausa de 90 segundos para que os participantes pudessem escrever todas as palavras que conseguissem lembrar que haviam sido apresentadas naquela lista, independentemente da seqüência original. Esse procedimento foi repetido sucessivamente para cada uma das 15 listas que compunham o bloco de palavras originais.

No Grupo de Reconhecimento, foi apresentado aos participantes o material original (todas as 15 listas de palavras de um dos blocos, em seqüência aleatória), sem intervalo, utilizando-se um aparelho de som e imediatamente após era entregue o teste de reconhecimento. Os participantes eram instruídos a lerem com atenção cada palavra do teste e a circularem apenas aquelas palavras que eles realmente tivessem escutado no material original.

\section{Análise dos Dados}

As respostas no teste de recordação livre foram quantificadas da seguinte forma: (a) índice de recordação verdadeira: número de palavras recordadas idênticas, ou com variação de gênero e número, àquelas do material original. Calculou-se a média de recordação verdadeira para cada um das 44 listas; (b) índice de recordação falsa: número de palavras críticas (que resumiam a essência semântica de cada uma das listas, p. exemplo, música) que foram falsamente recordadas como tendo sido apresentadas no material original. Computou-se então a média de recordação falsa para cada um das 44 listas.

Já no teste de reconhecimento, para os índices de respostas baseadas em memórias verdadeiras foram utili- 
zadas as médias de reconhecimento (responder "sim") aos itens-alvo, itens estes que foram apresentados no material original (por exemplo, som). Para as falsas memórias, utilizou-se a média de aceitação dos distratores críticos (palavras não apresentadas no material original e que resumiam a essência semântica das listas, por exemplo, música). Com o objetivo de verificar a qualidade da memória para o teste de reconhecimento, foi calculado o índice de respostas não mnemônicas (aceitação de distratores não relacionados).

\section{Resultados e Discussão}

\section{Recordação Livre}

Os resultados da condição de recordação livre, apresentados por lista nas Tabelas 1 e 2, são ordenados de forma decrescente de acordo com a proporção das intrusões críticas, ou seja, média de recordações falsas. A Tabela 1 apresenta as 22 listas que obtiveram maiores índices de recordação falsa, e a Tabela 2 inclui as 22 listas com menor produção de falsas recordações. A proporção média geral de evocações corretas foi $60 \%$, enquanto que a de falsas memórias foi $20 \%$ (última linha da Tabela 2 ).

\section{Tabela 1}

Listas com Maiores Índices de Falsas Memórias (T) no Teste de Recordação: Proporção dos Itens Recordados por Lista

Posição Serial

\begin{tabular}{|c|c|c|c|c|c|c|c|c|c|c|c|c|c|c|c|c|c|}
\hline Lista & 1 & 2 & 3 & 4 & 5 & 6 & 7 & 8 & 9 & 10 & 11 & 12 & 13 & 14 & 15 & MV & $\mathrm{T}$ \\
\hline Agulha & 57 & 76 & 72 & 31 & 52 & 55 & 64 & 47 & 60 & 50 & 78 & 60 & 66 & 50 & 90 & 60 & 67 \\
\hline Devagar & 88 & 53 & 34 & 81 & 40 & 22 & 7 & 29 & 78 & 29 & 48 & 52 & 64 & 79 & 95 & 53 & 52 \\
\hline Frio & 81 & 67 & 65 & 67 & 76 & 62 & 40 & 59 & 37 & 54 & 49 & 25 & 68 & 95 & 87 & 62 & 51 \\
\hline Lixo & 71 & 43 & 83 & 14 & 41 & 44 & 32 & 67 & 68 & 30 & 38 & 70 & 44 & 68 & 98 & 54 & 48 \\
\hline Cadeira & 83 & 96 & 80 & 63 & 51 & 43 & 46 & 37 & 24 & 63 & 53 & 47 & 43 & 70 & 64 & 58 & 46 \\
\hline Alto & 84 & 76 & 55 & 69 & 86 & 60 & 31 & 33 & 31 & 45 & 26 & 41 & 34 & 83 & 95 & 57 & 45 \\
\hline Dor & 67 & 38 & 46 & 32 & 16 & 32 & 46 & 56 & 63 & 27 & 65 & 52 & 83 & 62 & 97 & 52 & 44 \\
\hline Borracha & 94 & 60 & 89 & 61 & 43 & 56 & 64 & 46 & 77 & 66 & 41 & 51 & 53 & 69 & 90 & 64 & 34 \\
\hline Alegria & 72 & 57 & 84 & 24 & 62 & 81 & 33 & 59 & 59 & 59 & 41 & 26 & 72 & 95 & 98 & 61 & 33 \\
\hline Xícara & 98 & 90 & 78 & 74 & 62 & 66 & 36 & 43 & 57 & 62 & 53 & 66 & 41 & 83 & 90 & 67 & 31 \\
\hline Raiva & 88 & 60 & 28 & 28 & 22 & 21 & 60 & 74 & 26 & 24 & 19 & 34 & 78 & 71 & 100 & 49 & 29 \\
\hline Caneta & 68 & 71 & 83 & 68 & 49 & 59 & 27 & 76 & 51 & 57 & 33 & 43 & 83 & 56 & 90 & 61 & 29 \\
\hline Paixão & 98 & 78 & 48 & 40 & 31 & 91 & 47 & 7 & 88 & 83 & 63 & 50 & 60 & 71 & 98 & 63 & 28 \\
\hline Satisfação & 84 & 60 & 40 & 20 & 34 & 33 & 40 & 43 & 91 & 63 & 36 & 70 & 40 & 54 & 94 & 54 & 26 \\
\hline Macio & 97 & 63 & 79 & 70 & 84 & 36 & 54 & 36 & 26 & 51 & 80 & 26 & 70 & 81 & 91 & 63 & 26 \\
\hline Medo & 83 & 93 & 69 & 63 & 57 & 37 & 41 & 44 & 47 & 53 & 36 & 50 & 69 & 80 & 86 & 60 & 26 \\
\hline Ladrão & 86 & 81 & 74 & 69 & 67 & 36 & 33 & 19 & 57 & 40 & 22 & 62 & 71 & 67 & 72 & 57 & 24 \\
\hline Janela & 78 & 73 & 62 & 62 & 60 & 65 & 35 & 46 & 63 & 59 & 57 & 63 & 67 & 54 & 97 & 63 & 24 \\
\hline Música & 78 & 81 & 51 & 62 & 81 & 48 & 30 & 32 & 65 & 56 & 38 & 60 & 24 & 54 & 100 & 57 & 22 \\
\hline Cheirar & 93 & 73 & 80 & 66 & 37 & 27 & 93 & 36 & 70 & 27 & 63 & 86 & 77 & 86 & 74 & 66 & 20 \\
\hline Pé & 99 & 80 & 90 & 93 & 64 & 53 & 77 & 73 & 54 & 44 & 70 & 77 & 60 & 73 & 84 & 73 & 19 \\
\hline Doce & 93 & 76 & 84 & 29 & 57 & 59 & 60 & 33 & 59 & 60 & 80 & 90 & 74 & 86 & 93 & 69 & 19 \\
\hline$M$ & 84 & 70 & 67 & 54 & 53 & 49 & 45 & 45 & 57 & 50 & 50 & 55 & 61 & 72 & 90 & 60 & 34 \\
\hline
\end{tabular}

Notas. MV = Média de Recordação Verdadeira; $\mathrm{T}=$ Média de Intrusões Críticas. 
Stein, L.M.; Feix, L.F., \& Rohenkohl, G. (2006). Avanços Metodológicos no Estudo das Falsas Memórias: Construção e Normatização do Procedimento de Palavras Associadas.

Tabela 2

Listas com Menores Índices de Falsas Memórias (T) no Teste de Recordação: Proporção dos Itens Recordados por Lista

\begin{tabular}{|c|c|c|c|c|c|c|c|c|c|c|c|c|c|c|c|c|c|}
\hline \multirow{2}{*}{ Lista } & \multicolumn{9}{|c|}{ Posição Serial } & \multirow[b]{2}{*}{10} & \multirow[b]{2}{*}{11} & \multirow[b]{2}{*}{12} & \multirow[b]{2}{*}{13} & \multirow[b]{2}{*}{14} & \multirow[b]{2}{*}{15} & \multirow[b]{2}{*}{ MV } & \multirow[b]{2}{*}{$\mathrm{T}$} \\
\hline & 1 & 2 & 3 & 4 & 5 & 6 & 7 & 8 & 9 & & & & & & & & \\
\hline Menina & 87 & 89 & 56 & 63 & 71 & 54 & 21 & 41 & 33 & 41 & 56 & 51 & 63 & 57 & 92 & 58 & 19 \\
\hline Preto & 91 & 91 & 60 & 48 & 40 & 69 & 17 & 5 & 34 & 14 & 48 & 84 & 21 & 93 & 97 & 54 & 17 \\
\hline Dormir & 63 & 79 & 10 & 46 & 60 & 30 & 57 & 19 & 35 & 57 & 51 & 46 & 25 & 81 & 98 & 51 & 17 \\
\hline Culpa & 81 & 50 & 30 & 50 & 21 & 37 & 31 & 54 & 27 & 33 & 66 & 21 & 59 & 84 & 93 & 49 & 16 \\
\hline Carro & 68 & 75 & 57 & 54 & 48 & 38 & 59 & 51 & 46 & 52 & 6243 & 57 & 83 & 97 & 59 & 16 & \\
\hline Homem & 98 & 82 & 53 & 38 & 76 & 33 & 34 & 20 & 42 & 65 & 40 & 76 & 69 & 66 & 90 & 59 & 16 \\
\hline Montanha & 80 & 90 & 57 & 73 & 50 & 74 & 53 & 60 & 54 & 51 & 59 & 74 & 63 & 94 & 96 & 69 & 13 \\
\hline Fumar & 99 & 50 & 83 & 66 & 84 & 37 & 64 & 73 & 50 & 71 & 90 & 57 & 61 & 97 & 90 & 72 & 13 \\
\hline Pão & 68 & 75 & 52 & 78 & 68 & 43 & 52 & 57 & 44 & 49 & 57 & 73 & 78 & 95 & 87 & 65 & 13 \\
\hline Bandeira & 61 & 49 & 64 & 60 & 37 & 73 & 50 & 69 & 63 & 44 & 63 & 56 & 90 & 87 & 94 & 64 & 11 \\
\hline Camisa & 74 & 84 & 64 & 76 & 80 & 46 & 63 & 86 & 67 & 61 & 61 & 71 & 86 & 80 & 94 & 73 & 11 \\
\hline Mágoa & 83 & 70 & 73 & 44 & 40 & 37 & 24 & 13 & 33 & 25 & 38 & 46 & 27 & 83 & 59 & 46 & 11 \\
\hline Rio & 86 & 83 & 57 & 66 & 29 & 50 & 47 & 48 & 43 & 50 & 40 & 79 & 52 & 64 & 98 & 59 & 10 \\
\hline Rei & 93 & 87 & 99 & 56 & 53 & 43 & 67 & 63 & 50 & 54 & 57 & 47 & 87 & 76 & 94 & 68 & 7 \\
\hline Aranha & 86 & 62 & 67 & 71 & 30 & 41 & 43 & 73 & 52 & 60 & 67 & 70 & 29 & 71 & 100 & 61 & 6 \\
\hline Alívio & 65 & 46 & 30 & 29 & 22 & 21 & 16 & 32 & 35 & 14 & 60 & 41 & 65 & 79 & 97 & 43 & 5 \\
\hline Fruta & 67 & 84 & 62 & 70 & 49 & 59 & 63 & 37 & 63 & 40 & 86 & 81 & 75 & 75 & 89 & 67 & 5 \\
\hline Leão & 97 & 84 & 64 & 34 & 45 & 14 & 69 & 48 & 34 & 64 & 57 & 60 & 50 & 72 & 91 & 59 & 3 \\
\hline Exército & 91 & 72 & 64 & 50 & 48 & 34 & 34 & 33 & 28 & 57 & 28 & 33 & 74 & 76 & 95 & 54 & 2 \\
\hline Áspero & 88 & 41 & 64 & 50 & 66 & 67 & 60 & 62 & 38 & 60 & 81 & 10 & 31 & 76 & 93 & 59 & $\mathrm{O}$ \\
\hline Doutor & 100 & 83 & 43 & 45 & 26 & 34 & 17 & 79 & 78 & 36 & 93 & 43 & 55 & 79 & 88 & 60 & $\mathrm{O}$ \\
\hline Cidade & 96 & 94 & 86 & 36 & 53 & 53 & 57 & 40 & 53 & 23 & 57 & 84 & 60 & 44 & 90 & 62 & $\mathrm{O}$ \\
\hline$M$ & 83 & 73 & 59 & 54 & 49 & 44 & 47 & 49 & 46 & 47 & 60 & 57 & 58 & 79 & 92 & 60 & 9 \\
\hline$M$ total & 84 & 72 & 63 & 54 & 52 & 48 & 46 & 47 & 50 & 49 & 54 & 56 & 59 & 75 & 91 & 60 & 10 \\
\hline
\end{tabular}

Notas. MV = Média de Recordação Verdadeira; T= Média de Intrusões Críticas; $M$ total= Média total das tabelas 1 e 2.

Sessenta e sete por cento das pessoas recordaram falsamente ter escutado a palavra Agulha (Tabela 1), ainda que esta palavra não fosse apresentada no material original. Entretanto, as palavras críticas, como áspero, doutor e cidade, não foram falsamente lembradas por nenhum dos participantes (Tabela 2). Com relação às recordações corretas, as listas de palavras que apresentaram maiores índices de memórias verdadeiras foram $P e ́(M=73 \%)$ e Camisa $(M=73 \%)$. Já a lista Alívio $(M=43 \%)$ produziu o menor índice de recordações verdadeiras. $\mathrm{O}$ fato das 44 listas terem produzido resultados tão distintos no que concerne à avaliação de falsas memórias, bem como de memórias verdadeiras, traduz a riqueza potencial do material desenvolvido no senti- do de permitir que possam ser delineados diferentes experimentos que se utilizem desse instrumental.

Nossos resultados foram compatíveis com aqueles de Stadler et al. (1999), ainda que existam diferenças nos índices de falsas recordações. Em nosso estudo, os índices médios gerais de falsas recordações foram menores ( $M=20 \%)$, em comparação aos achados de Stadler et al. $(M=40 \%)$.

A Figura 1 apresenta a média geral de evocações corretas (para todas as 44 listas) no teste de recordação livre, tendo em vista a posição serial da palavra no material original. Como se pode observar, foi produzido o clássico efeito da posição serial (Murdock, 1962), incluindo os efei- 
tos de primazia e de recência, respectivamente, maior lembrança dos primeiros e dos últimos itens da lista de palavras original. O efeito da posição serial pode ser explicado pela Teoria da Interferência, a qual postula que os itens intermediários da lista são mais esquecidos, pois são os únicos que estão sujeitos a ambos tipos de interferência, quais sejam, retroativa e proativa (ver mais detalhes em Pergher, \& Stein, 2003).

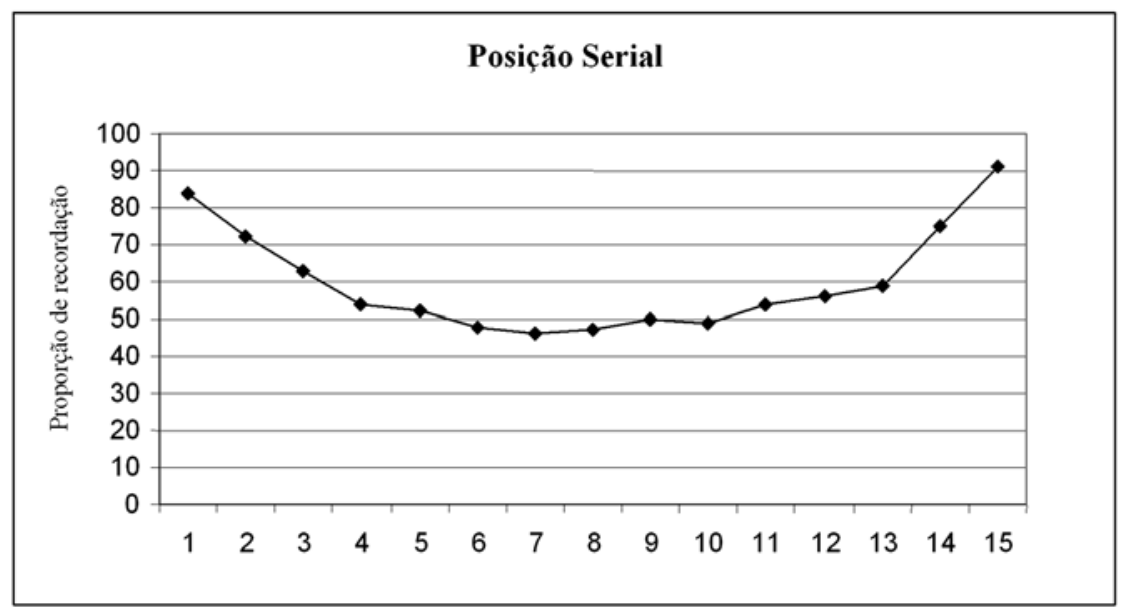

Figura 1. Proporção de recordações verdadeiras em função da posição serial dos itens.

\section{Reconhecimento}

Os dados concernentes à condição de teste de reconhecimento são apresentados nas Tabelas 3 e 4, em ordem decrescente, tendo em vista a proporção de aceitação dos distratores críticos (índices de falsas memórias). Cabe ressaltar que ao contrário do estudo de Stadler et al. (1999), cujos dados foram produzidos a partir de dois testes de memória (primeiro de recordação livre seguido de um teste de reconhecimento), nós evitamos o conhecido efeito de uma testagem anterior sobre os resultados no teste de reconhecimento (Brainerd \& Mojardin, 1998; Neufeld \& Stein, 2003), visto que os participantes do presente estudo somente realizaram um dos dois tipos de teste de memória. Dessa maneira, os resultados apresentados aqui se referem somente aos participantes que foram submetidos à condição de reconhecimento.

Tabela 3

Listas com Maiores Índices de Falsas Memórias (T) no Teste de Reconhecimento: Proporção de Aceitação dos Itens

\begin{tabular}{|c|c|c|c|c|c|}
\hline \multirow[b]{2}{*}{ Lista } & \multirow[b]{2}{*}{1} & \multicolumn{2}{|c|}{ Posição Serial } & \multirow[b]{2}{*}{ MV } & \multirow[b]{2}{*}{$\mathrm{T}$} \\
\hline & & 8 & 10 & & \\
\hline Música & 85 & 65 & 69 & 73 & 81 \\
\hline Cadeira & 65 & 62 & 79 & 69 & 79 \\
\hline Ladrão & 83 & 76 & 67 & 75 & 71 \\
\hline Lixo & 82 & 69 & 71 & 74 & 71 \\
\hline Fumar & 86 & 81 & 87 & 85 & 68 \\
\hline Frio & 47 & 71 & 60 & 59 & 66 \\
\hline Agulha & 61 & 46 & 62 & 56 & 61 \\
\hline Caneta & 54 & 88 & 64 & 68 & 61 \\
\hline Fruta & 89 & 58 & 77 & 75 & 57 \\
\hline Alto & 52 & 32 & 49 & 44 & 54 \\
\hline Dormir & 48 & 39 & 32 & 40 & 54 \\
\hline Mágoa & 80 & 52 & 69 & 67 & 54 \\
\hline Dor & 74 & 50 & 71 & 65 & 54 \\
\hline Doce & 63 & 53 & 47 & 54 & 53 \\
\hline
\end{tabular}


Stein, L.M.; Feix, L.F., \& Rohenkohl, G. (2006). Avanços Metodológicos no Estudo das Falsas Memórias: Construção e Normatização do Procedimento de Palavras Associadas.

\begin{tabular}{llllll} 
Homem & 75 & 37 & 66 & 59 & 52 \\
Exército & 58 & 58 & 58 & 58 & 52 \\
Medo & 46 & 60 & 59 & 55 & 52 \\
Borracha & 45 & 43 & 41 & 43 & 52 \\
Raiva & 71 & 47 & 28 & 49 & 51 \\
Menina & 82 & 42 & 50 & 58 & 50 \\
Paixão & 73 & 48 & 77 & 66 & 49 \\
Montanha & 38 & 44 & 51 & 44 & 49 \\
$M$ & 66 & 56 & 61 & 61 & 59 \\
\hline
\end{tabular}

Notas. MV = proporção média de reconhecimento dos itens 1, 8 e 10;

$\mathrm{T}=$ média de reconhecimento do distrator crítico.

Tabela 4

Listas com Menores Índices de Falsas Memórias (T) no Teste de Reconhecimento:

Proporção de Aceitação dos Itens

\begin{tabular}{|c|c|c|c|c|c|}
\hline \multirow[b]{2}{*}{ Lista } & \multirow[b]{2}{*}{1} & \multicolumn{2}{|c|}{ Posição Serial } & \multirow[b]{2}{*}{ MV } & \multirow[b]{2}{*}{$\mathrm{T}$} \\
\hline & & 8 & 10 & & \\
\hline Áspero & 72 & 38 & 38 & 49 & 48 \\
\hline Janela & 52 & 34 & 46 & 44 & 48 \\
\hline Pé & 72 & 59 & 59 & 63 & 48 \\
\hline Satisfação & 73 & 55 & 68 & 65 & 44 \\
\hline Bandeira & 64 & 57 & 48 & 56 & 43 \\
\hline Xícara & 51 & 47 & 50 & 49 & 42 \\
\hline Carro & 47 & 46 & 54 & 49 & 42 \\
\hline Alegria & 50 & 43 & 64 & 53 & 41 \\
\hline Macio & 74 & 78 & 76 & 76 & 40 \\
\hline Devagar & 72 & 30 & 30 & 44 & 36 \\
\hline Camisa & 48 & 53 & 43 & 48 & 36 \\
\hline Alívio & 42 & 50 & 31 & 41 & 34 \\
\hline Cidade & 38 & 36 & 40 & 38 & 34 \\
\hline Preto & 63 & 27 & 34 & 41 & 33 \\
\hline Pão & 69 & 53 & 50 & 57 & 30 \\
\hline Rio & 44 & 43 & 46 & 44 & 29 \\
\hline Cheirar & 60 & 28 & 28 & 39 & 28 \\
\hline Culpa & 60 & 56 & 47 & 54 & 27 \\
\hline Rei & 66 & 47 & 41 & 52 & 21 \\
\hline Leão & 49 & 52 & 58 & 53 & 17 \\
\hline Aranha & 54 & 58 & 54 & 56 & 17 \\
\hline Doutor & 63 & 41 & 43 & 49 & 14 \\
\hline$M$ & 58 & 47 & 48 & 51 & 34 \\
\hline$M$ total & 62 & 51 & 54 & 56 & 46 \\
\hline
\end{tabular}

Notas. MV = proporção média de reconhecimento dos itens 1,8 e 10; $M$ total = Média total das tabelas 3 e $4 ; \mathrm{T}$ = média de reconhecimento do distrator crítico. 
A Tabela 3 mostra as 22 listas que produziram maiores índices de falsas memórias e a Tabela 4 as 22 listas que obtiveram menores índices. $\mathrm{O}$ distrator crítico música foi falsamente reconhecido por $81 \%$ dos participantes como tendo sido apresentado no material original, seguido por Cadeira $(M=79 \%)$, Ladrão $(M=71 \%)$ e Lixo $(M=71 \%)$. Contudo, as listas Doutor $(M=14 \%)$, Aranha $(M=17 \%)$ e Leão $(M=17 \%)$ obtiveram menor aceitação de distratores críticos, portanto menor produção de falsas memórias.

Com relação às memórias verdadeiras, a maior aceitação dos itens alvos por lista ocorreu em Fumar ( $M=85 \%$ ), seguido por Macio ( $M=76 \%)$, Ladrão $(M=75 \%)$ e Fruta $(M=75 \%)$. As listas Cidade $(M=38 \%)$ e Cheirar $(M=39 \%)$ produziram menores índices de memórias verdadeiras.

Quando examinadas as 44 listas como um todo, observou-se que a proporção média geral de aceitação dos distratores críticos $M=46 \%$ (última linha da Tabela 4) foi bastante próxima da aceitação de alvos que foi de $56 \%$. Em relação aos distratores não relacionados, ou seja, respostas dadas sem base mnemônica, observou-se uma média de respostas para esse tipo de item praticamente insignificante $(M=5 \%)$.Com relação as 22 listas que produziram efeitos mais robustos de falsas memórias (Tabela 3), observamos que houve um emparelhamento entre a proporção média de aceitação dos distratores críticos $(M=$ $59 \%)$ e o reconhecimento dos alvos $(M=61 \%)$. Todavia, com relação às listas menos robustas (Tabela 4) o índice médio geral de falso reconhecimento $(M=34 \%)$ foi menor do que o de memórias verdadeiras $(M=51 \%)$. Os dados obtidos no Estudo 2 estão plenamente alinhados com resultados encontrados na literatura na área (p. ex., Stadler et al., 1999), o que indica uma boa validade do material e procedimentos desenvolvidos.

Finalmente, foi investigada a possível relação entre as falsas recordações e os falsos reconhecimentos para a mesma lista de palavras associadas. O teste de correlação de Pearson indicou que existe uma associação significativa entre os indicadores de falsas memórias $(r=0,50, n=$ $44, p<0,01)$. Esse resultado sugere haver uma tendência, na qual a produção de falsas memórias por lista seja independente da natureza do teste de memória. Contudo, o mesmo resultado não foi observado no que diz respeito às memórias verdadeiras $(r=0,09, n=44, p>0,05)$. Esses achados também foram verificados em Stadler et al. (1999). Portanto, independentemente da natureza do teste de memória, seja recordação livre ou reconhecimento, as listas de palavras que tendem a produzir mais falsas memórias são similares.

\section{Conclusões Gerais}

Os resultados dos dois estudos oferecem subsídios metodológicos valiosos para os pesquisadores da memória humana. O material produzido e os resultados em termos tanto da testagem das memórias verdadeiras, mas fundamentalmente, em relação às falsas memórias, representa mais um significativo avanço dentro do esforço que pesquisadores brasileiros têm feito no sentido de gerar ins- trumental e procedimentos científicos adequados a nossa realidade cultural.

O consagrado procedimento com listas de palavras associadas foi recentemente denominado por Endel Tulving como o paradigma DRM, em referência às iniciais dos autores Deese-Rodieger-McDermott, sigla pronunciada em inglês dream que significa sonho ou sonhar (ver Roediger, McDermott, \& Robinson, 1998). Talvez o sonho, a que quis referir-se Tulving, esteja ligado ao fato das inúmeras possibilidades que o Procedimento de Palavras Associadas permite para o estudo das ilusões mnemônicas (objetivo tão sonhado por pesquisadores da área), tanto em termos de falso reconhecimento quanto de falsa recordação.

Embora o fenômeno de falso reconhecimento tenha sido foco principal de estudo por pesquisadores do mundo, o Procedimento de Palavras Associadas ampliará as investigações futuras no campo da memória, uma vez que suporta experimentos envolvendo recordação livre e teste reconhecimento para o mesmo material. A riqueza do Procedimento de Palavras Associadas para o estudo da memória e seus processos de distorção reside justamente na produção de efeitos robustos de falsas memórias. Por exemplo, mesmo quando os participantes são avisados sobre a natureza das distorções de memória, ou estão cientes sobre os procedimentos envolvidos para inflacionar os ín-dices de distorção de memória, ainda assim acabam por produzir altos índices de falsas memórias (Gallo, Roberts \& Seamon, 1997).

Enfim, ao oferecermos aos pesquisadores de Língua Portuguesa um material adequado a nossa realidade, fornecendo conhecimentos detalhados acerca das características das listas em situação de testagem da memória, almejamos possibilitar aos investigadores da memória responder novas questões sobre o fenômeno da distorção da memória, entre outros. Ainda, ao equiparmos a comunidade científica de língua portuguesa com este manancial de informações acerca da efetividade das listas de palavras associadas em criar falsas memórias, estamos de certa forma lançando a base para que os pesquisadores possam realizar suas investigações em condições de igualdade daqueles que já há muito se beneficiam do paradigma DRM (na língua inglesa).

\section{Referências}

Anastasi, J. S., Rhodes, M. G., \& Burns, M. C. (2000). Distinguishing between memory illusions and actual memories using phenomenological measurements and explicit warnings. The American Journal of Psychology, 113, 1-26.

Balota, D. A., Cortese, M. J., Duchek, J. M., Adams, D., Roediger, H. L., McDermott, K. B., \& Yerys, B. E. (1999). Veridical and false memories in healthy older adults and in dementia of the alzheimer's type. Cognitive Neuropsychology, 16(3-5), 361-384.

Bartlett, F. C. (1932). Remembering: A study in experimental and social psychology. London: Cambridge University Press.

Brainerd, C. J., \& Mojardin, A. H. (1998). Children's spontaneous false memories for narrative statements: Long-term persistence and meretesting effects. Child Development, 69, 1361-1377. 
Bruce, D., \& Winograd, E. (1998). Remembering Deese's 1959 articles: The Zeitgeist, the Sociology of Science, and false memories. Psychonomic Bulletin \& Review, 5(4), 615-624.

Ceci, S. J., \& Bruck, M. (1993). The suggestibility of the child witness: A historical review and synthesis. Psychological Bulletin, 113, 403-439.

Deese, J. (1959). On the prediction of occurrence of particular verbal intrusions in immediate recall. Journal of Experimental Psychology, 58, 17-22.

Dodson, C. S., \& Schacter, D. L. (2002). Aging and strategic retrieval processes: Reducing false memories with a distinctiveness heuristic. Psychology and Aging, 17(3), 405-415.

Ekman, P. (1999). Basic emotions. In T. Dalgleish \& M. Power (Eds.), Handbook of cognition and emotion (pp. 45-60). New York: John Wiley \& Sons.

Ferreira, A. B. H. (1999). Aurélio século XXI: O dicionário da língua portuguesa. Rio de Janeiro, RJ: Nova Fronteira.

Gallo, D. A., Roberts, M. J., \& Seamon, J. G. (1997). Evaluating characteristics of false memories: Remember/know judgement and memory characteristics questionnaire compared. Memory \& Cognition, 25, 826-837.

Gallo, D. A., \& Roediger, H. L. (2002). Variability among word lists in eliciting memory illusions: Evidence for associative activation and monitoring. Journal of Memory and Language, 47, 469-497.

Heckler, E. (1984). Dicionário morfológico da língua portuguesa (Vols. 1-5). São Leopoldo, RS: Editora da Universidade do Vale do Rio dos Sinos.

Janczura, G. A. (1996). Normas associativas para 69 categorias semânticas. Psicologia: Teoria e Pesquisa, 12(3), 237-244.

Murdock, B. B., Jr. (1962). The Serial position effect of free recall. Journal of Experimental Psychology, 64, 482-488.

Neufeld, C. B., \& Stein, L. M. (2003). Falsas memórias em préescolares: Uma investigação experimental e suas implicações. In M. Z. S. Brandão, F. C. S. Conte, F. S. Brandão, Y. K. Ingberman, C. B. Moura, V. M. Silva \& S. M. Olione (Eds.), Sobre comportamento e cognição: Clínica, pesquisa e aplicação (Vol. 12, pp. 453-468). Santo André, SP: ESETec.

Neuschatz, J. S., Benoit, G. E., \& Payne, D. G. (2003). Effective warnings in the Deese-Roediger-McDermott false-memory paradigm: The role of identifiability. Journal of Experimental Psychology: Learning, Memory and Cognition, 29(1), 35-41.

Pergher, G. K., \& Stein, L. M. (2003). Compreendendo o esquecimento: Teorias clássicas e seus fundamentos experimentais. Psicologia USP, 14(1), 129-155.

Roediger, H. L., III (1996). Memory illusions. Journal of Memory and Language, 35, 76-100.

Roediger, H. L., III, \& McDermott, K. B. (1995). Creating false memories: Remembering words not presented on lists. Journal of Experimental Psychology: Learning; Memory, and Cognition, 21, 803-814.

Roediger, H. L., III, McDermott, K. B., \& Robinson, K. J. (1998). The Role of associative process in creating false memories. In M. A. Conway, S. E. Gathercole \& C. Cornoldi (Eds.), Theories of memory II (pp. 187-246). Hove, UK: Psychological Press.

Russell, W. A., \& Jenkins, J. J. (1954). The complete Minnesota norms for responses to 100 words from the Kent-Rosanoff Association Test. Minneapolis, MN: University of Minnesota.

Social Sciences Citation Index. (2005). Retirado em 29 de setembro de 20005, em http://www.isiknowledge.com

Stadler, M. A., Roediger, H. L., \& McDermott, K. B. (1999). Norms for words that create false memories. Memory $\xi^{\circ}$ Cognition, 27, 494-500.
Stein, L. M., \& Neufeld, C. B. (2001). Falsas memórias: Porque lembramos de coisas que não aconteceram? Arquivos de Ciências da Saúde, 5(2), 179-186.

Stein, L. M., \& Pergher, G. K. (2001). Criando falsas memórias em adultos por meio de palavras associadas. Psicologia: Reflexão e Crítica, 14(2), 353-366.

Watson, J. M., Balota, D. A., \& Roediger, H. L. (2003). Creating false memories with hybrid lists of semantic and phonological associates: Over-additive false memories produced by converging associative networks. Journal of Memory and Language, 49(1), 95-118.

Watson, J. M., McDermott, K. B., \& Balota, D. A. (2004). Attempting to avoid false memories in the Deese/RoedigerMcDermott paradigm: Assessing the combined influence of practice and warnings in young and old adults. Memory $\xi^{\circ}$ Cognition, 32(1), 135-141.

\section{ANEXO A}

Listas de palavras associadas, em ordem decrescente de associação semântica com a palavra crítica, criadas no Estudo I

(1) Agulha: costura, linha, fina, ponta, furar, injeção, seringa, espetar, tricô, bordar, palheiro, máquinas, metal, fio, fincar. (2) Alegria: sorriso, felicidade, festa, vida, amigos, família, paz, nascimento, filhos, euforia, pular, diversão, sucesso, carnaval, gol. (3) Alívio: bom, descanso, tranqüilidade, suspiro, fim, leveza, sensação, relaxamento, sossego, despreocupação, férias, respirar, sufoco, vitória, tensão. (4) Alto: baixo, prédio, grande, comprido, edifício, céu, imponente, longe, distante, estatura, difícil, elevado, tamanho, magro, gigante. (5) Aranha: teia, veneno, inseto, peluda, perigo, nojo, feia, patas, pernas, picada, mosca, peçonha, bicho, mordida, asquerosa. (6) Áspero: lixa, ruim, chão, pedra, asfal to, duro, grosso, mão, rude, parede, rugoso, escova, atrito, areia, superfície. (7) Bandeira: pátria, símbolo, nação, mastro, país, verde, pano, hino, flâmula, honra, identificação, representação, amarelo, haste, estado. (8) Borracha: apagar, erro, lápis, corrigir, limpar, látex, escola, farelo, borrar, elástica, desenho, colégio, flexível, estica, desfazer. (9) Cadeira: sentar, mesa, madeira, objeto, comodidade, sala, balanço, móvel, encosto, aula, estofado, apoio, poltrona, banco, decoração. (10) Camisa: roupa, botão, vestir, manga, gola, tecido, social, futebol, gravata, xadrez, calça, moda, passada, curta, bolso. (11) Caneta: escrever, tinta, azul, papel, útil, caderno, comunicação, esferográfica, estojo, prova, riscar, assinatura, tampa, carta, material. (12) Carro: transporte, velocidade, motor, locomoção, rodas, viagem, pneu, status, automóvel, necessidade, estrada, novo, direção, rápido, gasolina. (13) Cheirar: perfume, nariz, odor, flor, olfato, aroma, cocaína, fragrância, lembrança, rosas, pó, aspirar, espirro, faro, gripe. (14) Cidade: casa, pessoas, ruas, movimento, população, urbanização, agito, moradia, barulho, lugar, maravilhosa, metrópole, comércio, habitantes, multidão. (15) Culpa: arrependimento, consciência, remorso, mal-estar, jul gamento, peso, traição, pecado, agonia, crime, responsabilidade, mentira, acusar, conseqüência, repressão. (16) Devagar: lento, calma, parar, tartaruga, caminhar, cuidado, demora, andar, trânsito, atenção, lerdo, paciência, preguiça, lesma, atraso. (17) Doce: açúcar, gos- 
toso, chocolate, sabor, mel, sorvete, delícia, bala, salgado, guloseima, diabetes, gordura, cárie, torta, paladar. (18) Dor: sofrimento, machucado, perda, choro, incômodo, ferida, remédio, dente, cabeça, saudade, sangue, acidente, analgésico, insuportável, desespero. (19) Dormir: sonhar, cama, repouso, acordar, pesadelo, essencial, acompanhado, deitado, energia, cedo, cochilar, rede, silêncio, tarde, bocejo. (20) Doutor: médico, doença, respeito, sabedoria, estudo, profissional, cura, hospital, advogado, confiança, especialista, consultório, título, formado, superior. (21) Exército: soldado, armas, guerra, disciplina, farda, ordem, militar, marcha, defesa, uniforme, proteção, organização, rigidez, batalha, quartel. (22) Frio: gelo, inverno, casaco, neve, cobertor, agasalho, blusa, aconchego, temperatura, calor, arrepio, chuva, lã, lareira, sopa. (23) Fruta: saudável, maçã, vitamina, banana, morango, suco, laranja, madura, pêra, nutritiva, melancia, suculenta, uva, salada, pêssego. (24) Fumar: cigarro, vício, câncer, prejudicial, pulmão, droga, horrível, charuto, tosse, nicotina, maconha, cinza, isqueiro, tragar, tabaco. (25) Homem: mulher, inteligente, racional, pai, masculino, trabalho, ser, barba, músculos, capaz, marido, macho, corajoso, companheiro, namorado. (26) Janela: vidro, cortina, paisagem, abertura, vento, luz, visão, ar, sol, porta, persiana, claridade, horizonte, grade, veneziana. (27) Ladrão: roubo, prisão, assalto, polícia, cadeia, desonesto, bandido, insegurança, dinheiro, furto, pobreza, revólver, fuga, corrupção, delinqüente. (28) Leão: feroz, juba, selva, forte, animal, bravo, signo, carnívoro, zoológico, felino, rugido, caça, circo, garras, jaula. (29) Lixo: sujeira, reciclagem, fedor, resto, lata, saco, poluição, orgânico, seco, desperdício, problema, podre, cesto, descartável, coleta. (30) Macio: travesseiro, confortável, fofo, colchão, sofá, agradável, algodão, suave, almofada, ursinho, colo, edredom, pele, bolo, abraço. (31) Mágoa: tristeza, sentimento, lágrima, rancor, decepção, desilusão, frustração, esquecida, chata, amargura, marca, atitude, infidelidade, melancolia, carência. (32) Medo: escuro, morte, solidão, angústia, pânico, susto, desconhecido, pavor, violência, fobia, grito, terror, trauma, tremor, temor. (33) Menina: bonita, boneca, criança, saia, meiga, feminina, brincadeira, inocência, pequena, cabelo, jovem, delicada, frágil, infância, pureza. (34) Montanha: escalada, natureza, beleza, árvores, liberdade, alpinismo, aventura, subir, rocha, russa, obstáculo, serra, terra, pico, morro. (35) Música: som, dança, disco, ritmo, melodia, cantor, letra, rádio, violão, instrumentos, notas, harmonia, ouvir, voz, guitarra. (36) Paixão: amor, carinho, loucura, fogo, coração, sexo, desejo, emoção, tesão, beijo, ardente, alguém, ansiedade, afeto, cega. (37) Pão: alimento, fome, comida, farinha, manteiga, quente, massa, trigo, sanduíche, queijo, francês, carboidratos, margarina, fermento, lanche. (38) Pé: dedos, sapato, unha, chulé, meia, calçado, tênis, sustentação, chinelo, calo, base, calcanhar, corpo, chute, pisar. (39) Preto: cor, branco, noite, raça, luto, negro, ausência, básico, gato, nada, preconceito, velório, sombra, fúnebre, discriminação. (40) Raiva: ódio, ira, briga, fúria, descontrole, vermelho, cachorro, agressão, momento, nervosismo, irritação, injustiça, vingança, cólera, negativo. (41) Rei: coroa, poder, rainha, riqueza, castelo, autoridade, trono, monarquia, majestade, soberano, império, nobreza, palácio, dono, líder. (42) Rio: água, peixe, correnteza, fundo, banho, nadar, pesca, margem, barco, frescor, belo, livre, lagoa, cachoeira, ponte. (43) Satisfação: prazer, bem-estar, realização, contente, conquista, orgulho, completude, gozo, plenitude, objetivo, glória, conseguir, animação, competência, entusiasmo. (44) Xícara: café, chá, pires, porcelana, beber, leite, louça, asa, tomar, colher, cozinha, bule, copo, quebrada, medida.
Recebida: 01/12/2004

1 revisão: 08/08/2005

2 revisão: 13/10/2005 Aceite final: 08/11/2005 